\title{
Zum Tod von Charles Aznavour am 1. Oktober 2018
}

\author{
Gerd HEGER (Saarbrüicken) ${ }^{1}$
}

Man nannte ihn Aznovoice, die kleine Goldnuschel. Und er fand, das sei ein gutes Wortspiel. Zumindest, als er längst auf der Umlaufbahn war als Weltstar, von der ihn kein Kritikerwort mehr herunterholen konnte.

Am letzten Donnerstag im Dezember 1933 stand er zum ersten Mal auf einer großen Bühne, im Palais Chaillot in Paris - der neunjährige Charles, Kind einer armenischen Auswanderer-familie. Man lebte in einer Wohnung von nicht einmal 30 Quadratmetern. Dennoch hatte der alte Herr, wie er in einem Interview im Saarländischen Rundfunk offenbarte, eine wunderbare Kindheit in Erinnerung: „Liebe, Lachen, Singen, Theater, Kino auch. Es gab russische und armenische Schauspieler [...], die Auftritte organisierten meine Eltern."

Ein Gigant. Eine Legende. Einer der größten Entertainer des 20. Jahrhunderts (und darüber hinaus). Letzter großer Chansonkünstler der klassischen Zeit. Über 60 Filme. Mehr als 1000 Chansons in vielen Sprachen, mehr als 100 Millionen verkaufte Alben, unzählige Konzerte. Superlative für den kleinen Mann mit der einstmals so großen Nase, die er sich kurz nach dem 2. Weltkrieg in Amerika operieren ließ.

Auf der Bühne lieferte er sich aus, setzte „[s]ein Herz ein“. Im Leben ging er mit Kraft ans Werk, mit Wut, mit einem Antrieb, der ihn sein Leben lang nicht los ließ. Und auch wenn der Durchbruch über Jahrzehnte nicht kam, er wusste es, wie er in „Je m’voyais déjä“ sang, dass er Talent hatte. Und viel mehr.

Edith Piaf hat Charles Aznavour entdeckt - ein Standardsatz aus jeder Biographie. Wahr ist: Er gehörte eine Zeitlang zum Piaf-Hofstaat. Sie sang Lieder von ihm, brachte ihn und seinen damaligen Duopartner Pierre Roche nach Amerika. Sie förderte ihn zunächst mehr als Autor, sah ihn nicht als Sänger, war dann aber doch sehr gerührt, als er endlich Erfolg hatte. Eine amouröse Freundschaft, das verband Aznavour und Piaf. Überhaupt Freundschaft - Aznavour war ein echter Freund. Liza Minelli hat einen Schlaganfall? Aznavour steht am nächsten Tag in Amerika neben ihrem Krankenbett. Sammy Davis Junior in Person war Trauzeuge der seit über 50 Jahre haltenden Ehe Aznavours. Frankreichs Elvis Johnny Hallyday wird siebzig? Aznavour hält das Mikro mit zitternden Händen, singend mit ihm auf der Bühne. Die Liste ist endlos.

Ruhig, sanft - eine zärtliche Landschaft: der Blick aus Aznavours Haus am Genfer See. Dort wohnte der armenische Botschafter - in der Schweiz und bei der UNO. Spätestens seit 
dem Erdbeben 1988 war Charles Aznavourian (so sein Geburtsname) einer der wichtigsten internationalen Repräsentanten des Heimatlandes seiner Vorfahren. So traf er Präsidenten, Könige und Potentaten - auch in der Türkei. Und kämpfte für die Anerkennung des Völkermords an den Armeniern 1915/1916.

Eine Stimme im Konzert der Nationen - in diesem Fall ist das Bild wirklich berechtigt. Und das mit dieser Stimme.

Arbeitstier Aznavour. Schreiben, das waren Ferien für ihn. Ausruhen? Ein Fremdwort für ihn. Immer wieder zog es ihn auf die Bühne: Noch Tage vor seinem überraschenden Tod in seinem provenzalischen Zweitwohnsitz in den Alpilles stand er in Japan auf der Bühne.

Und so verstand man das Chansonwunder Aznavour nur ganz, wenn man ihn auf der Bühne gesehen hatte. Einen singenden Schauspieler nannte er sich. Ein ,cooler' alter Herr voller Feuer war er, ganz da, ganz nah und nie unnahbar. Für Rocker, Rapper und Slammer genau wie für die alte Pariser Dame im siebzehnten Rang, die jeden Moment ihres Lebens mit seinen Chansons verbinden konnte. Ein Magier, der mit dieser unglaublichen Stimme und seinen perfekten Liederperlen einem die Tränen in die Augen zauberte. Er verkörpert ganz allein das Chanson - diese typische französische Liedform, die so viel Wert auf Poesie und Leben legt. Das Geheimnis des Erfolgs, wie er es sieht: Beruf und Publikum lieben, diese paar Leute, mit denen man sich gut versteht. Und mit diesen eine echte Gemeinsamkeit aufbauen, Teil ihres Lebens werden, sie zu Komplizen machen. Charles Aznavour ist es Zeit seines langen Lebens gelungen, unser geliebter Chansonkomplize zu sein.

\section{Endnoten}

1 Gerd Heger, deutsch-französischer Radiojournalist beim Saarländischen Rundfunk, ist Mitgründer der Chansonkonzertreihe Bistrot Musique (nunmehr RendezVous Chanson live), Moderator und Programmgestalter von RendezVous Chanson, der einzigen wöchentlichen Chansonsendung im deutschen Radio, sowie Mitmoderator und -programmgestalter von Lieder und Chansons auf SR 3 Saarlandwelle. 